\title{
Student Motivation as Hierarchical and Multidimensional: Cross-cultural Validation of Personal Investment Theory in the Philippines*
}

Jerarquía y multidimensionalidad en la motivación de los estudiantes: validación intercultural de la Teoría de Inversión Personal en Filipinas

Recibido: abril 16 de 2012 | Revisado: noviembre 20 de 2012 | Aceptado: enero 13 de 2013

\author{
RONNEL BORNASAL KING ** \\ Nanyang Technological University, Singapore \\ Fraide Agustin Ganotice, JR. **** \\ Palawan State University, Puerto Princesa, Philippines
}

doi:10.11144/Javeriana.UPSY12-3.smhm

Para citar este artículo: King, R. B., \& Ganotice, F. A., Jr. (2013). Student motivation as hierarchical and multidimensional: Cross-cultural validation of personal investment theory in the Philippines. Universitas Psychologica, 12(3), 685-698. doi:10.11144/ Javeriana.UPSY12-3.smhm

* This research was partially funded by a CHED (Commission on Higher Education) PhD scholarship given by the Philippine government to the second author.

** Nanyang Technological University, Singapore. Correspondence concerning this article should be sent to: Dr. Ronnel Bornasal King. NIE 5-B3-62 Learning Sciences Laboratory, National Institute of Education, Nanyang Technological University. 1 Nanyang Walk, Singapore. Dr. King obtained his Ph.D. in Educational Psychology from The University of Hong Kong. His research interests are in cross-cultural investigations of student motivation, achievement, and well-being. Research ID: H-76322013.E-mail: ronnel.king@nie.edu.sg

**** College of Teacher Education and the Research Director of Palawan State University (Philippines). AssociateProfessor E-mail: fraideganotc@yahoo. com

\begin{abstract}
A B S T R A C T
Personal investment theory presents a hierarchical and multidimensional model of motivational goals that influence important academic outcomes. The aim of this study was to examine the cross-cultural validity of this model in the Philippine setting using both within- and between-network approaches to construct validation. Filipino high school $(N=823)$ students participated in the study. Their mean age was $14.28(S D=0.97)$. Confirmatory factor analysis supported the construct validity of the model. The eight types of first order goals (task, effort, competition, social power, social affiliation, social concern, praise, and token goals) formed four second-order goals (mastery, performance, social, and extrinsic), which in turn formed a third-order factor called global motivation. It was found that mastery, performance, and extrinsic were positively related to academic achievement. Social and extrinsic goals were positively related to affect to school. In general, the results supported the cross-cultural validity of the hierarchical and multidimensional model of student motivation in a non-Western context. This study highlights the importance of testing the validity of Western-oriented theories of achievement motivation before they are applied in non-Western settings.

Key words authors

Personal investment theory, achievement goals, Philippines, cross-cultural validation.

Key words plus

Quantitative Research, Validity, Educative Psychology.
\end{abstract}

\begin{abstract}
RE S U MEN
La teoría de investigación personal presenta un modelo jerárquico y multidimensional de los objetivos motivacionales que influencian los resultados académicos importantes. El objetivo de este estudio fue examinar la validez intercultural de este modelo en el contexto Filipino usando una aproximación de tanto dentro y entre redes para la validación de constructo. Estudiantes de secundaria filipinos $(N=823)$ participaron en el estudio. La edad media fue $14.28(D E=0.97)$. El análisis factorial confirmatorio soportó la validez de constructo del modelo. Los ocho tipos de objetivos de primer orden (tarea, esfuerzo, competición, poder social, afiliación social, preocupación social, alabanza y objetivos simbólicos) formaron cuatro objetivos de segundo orden (dominio, desempeño, social y extrínseco), que a su vez formaron un factor de tercer orden denominado motivación global. Se encontró que los objetivos de dominio, desempeño y extrínseco estaban positivamente relacionados con afecto hacia la escuela. En general, los resultados apoyan la validez intercultural del modelo jerárquico y multidimensional de la motivación de los
\end{abstract}


estudiantes en un contexto no-occidental. Este estudio resalta la importancia de evaluar la validez de teorías de orientación occidental acerca de la motivación de logro antes de que sean aplicadas en contextos no occidentales.

Palabras clave autores

Teorías de investigación personal, logro de objetivos, Filipinas, validación intercultural

Palabras clave adicionales

Investigación cuantitativa, validez, psicología educativa.

\section{Introduction}

Students have different goals in school. Some students go to school with the purpose of developing their skills and competence, while others focus on competing with their peers. There are those whose main goal is to be with their friends, and there are also those who want to get external rewards for studying. Decades of research in goal theory have confirmed that students' academic engagement in school is determined, to a large extent, by their goals (see for reviews, Covington, 2000; Elliot, 2005; Maehr \& Zusho, 2009). This indicates the important role played by students' goals, which are defined as the reasons for engagement or non-engagement in school-related tasks (Maehr, 1984; Pintrich, 2000).

In his landmark review of motivation research in psychology, Pintrich (2003) posited the question, "What motivates students in school?" Achievement goal theory has attempted to answer this question by focusing on the role of mastery and performance goals in motivating students (Ames, 1992; Dweck \& Leggett, 1988). However, some researchers have pointed out the limitations of achievement goal theory and proposed that there are other types of goals (e.g. extrinsic goals and social goals) that are relevant in the school setting (Boekaerts, 2006, 2009; King \& McInerney, 2012; King, McInerney, \& Watkins, 2012b; King \& Watkins, 2011, 2012a, 2012b; Urdan \& Maehr, 1995). This issue became especially relevant when educational psychologists started investigating students from different cultural contexts, where they found that mastery and performance goals were unable to fully capture the complexity of students' goals (King, McInerney, \& Watkins, 2012b, 2013; King \& Watkins, 2011; Tao, 2003; Tao \& Hong, 2000; Yu \& Yang 1994). As Eccles, Wigfield, and Schiefele (1998) put it, “categorizing children's goals as ego (performance) or task involved (mastery) over simplifies the complexity of motivation" (p. 1032).

One theory of motivation that was specifically designed to be applicable in cross-cultural settings is Personal Investment (PI) theory (Maehr \& McInerney, 2004; McInerney \& Ali, 2006; McInerney $\&$ Liem, 2009). This model is an extension of traditional achievement goal theory and proposes a wider range of goals assumed to be relevant across different cultural contexts. However, there is still a lack of studies examining the validity of this theory in different cultural contexts such as the Asian and Latin American settings. Therefore, the aim of this research is to further assess the cross-cultural validity of this multidimensional and hierarchical model of motivational goals proposed by PI Theory in the Philippine setting.

\section{Achievement Goal Theory}

Achievement goals have been conceptualized as the purpose of task engagement (Maehr \& Zusho, 2009). The original conceptualization of achievement goals is grounded in a distinction between mastery goals (also labelled as learning or task-involvement goals) and performance goals (also labelled as ego involvement or ability goals) (Ames, 1992; Dweck \& Leggett, 1988). Students who pursue mastery goals are focused on the development of task mastery and competence, while those who pursue performance goals emphasize the demonstration of competence relative to others (Ames, 1992). In recent years, the approach and avoidance components of mastery and performance goals have also been studied (for a historical review see, Elliot, 2005); however, the focus remains to be mastery and performance goals.

Achievement goal theory has become a dominant paradigm among educational psychologists leading to over 1,000 studies since its inception (Hulleman, Schrager, Bodmann, \& Harackiewicz, 2010). Pintrich (2003, p. 676) claimed that it was "one of the most active areas" in motivation research. Despite the popularity of achievement goal theory, a number of studies in cross-cultural psychology have 
shown that Western-derived theories of achievement motivation might not be generalizable to more collectivistic contexts. This theme has become more pronounced with the publication of volumes such as Research on the Sociocultural Influences on Motivation and Learning (McInerney \& Van Etten, 2004) and Research in Multicultural Education and International Perspectives (Salili \& Hoosain, 2007). Achievement goal theory has been criticized of being based on an individualistic interpretation of achievement strivings. Some cross-cultural researchers argue that in collectivist settings, there is a need to focus on more socially oriented types of goals (Dowson \& McInerney, 2001, 2003; King, McInerney, \& Watkins, 2012b, 2013; Tao, 2003; Urdan \& Maehr, 1995; Yang \& Yu, 1994). As such, achievement goal theory has been criticized because of its exclusive focus on individualistic types of goals. It fails to take into account social goals and other more extrinsic types of goals, which can also be powerful motivators of behaviour in collectivist cultures.

\section{Personal Investment Theory}

PI theory attempts to address some of the limitations of traditional achievement goal theory. McInerney and his colleagues (Maehr \& McInerney, 2004; McInerney \& Ali, 2006; McInerney \& Liem, 2009) proposed a hierarchical, multidimensional model of motivational goals designed to reflect a wider range of goals relevant for both Western and non-Western students. At the base of the model there are eight specific goals (task, effort, competition, social power, social concern, social affiliation, praise, and token), which can be grouped into four more general achievement goals (mastery, performance, social, and extrinsic). At the top of the hierarchy is global motivation. Table 1 presents the different types of goals proposed in PI Theory together with sample items used to measure these goals.

As shown in Table 1, PI theory takes into account mastery and performance goals, which are well researched in the traditional achievement goal literature. However, it also includes social and extrinsic goals, which are not well investigated. In arguing for the importance of social goals, Dowson and McInerney (2001, p. 40) claimed that "students' social orientations are not peripheral to... academic performance and achievement. Rather, these orientations may directly influence students' psychological processes as they strive toward academic achievement." Numerous studies have shown how social goals are linked

TABLE 1

Different Goals within the Personal Investment (PI) Framework

\begin{tabular}{|c|c|c|c|}
\hline Second-order goal & First-order goal & Definition & Sample items \\
\hline \multirow{2}{*}{ 1. Mastery goals } & Task & Interest in the task & $\begin{array}{l}\text { "The more interesting the schoolwork } \\
\text { the harder I try." }\end{array}$ \\
\hline & Effort & $\begin{array}{l}\text { Willingness to expend effort for } \\
\text { schoolwork }\end{array}$ & $\begin{array}{l}\text { I always try hard to understand some- } \\
\text { thing new in my schoolwork." }\end{array}$ \\
\hline \multirow{2}{*}{ 2. Performance goals } & Competition & Competitiveness in learning & $\begin{array}{l}\text { "I like to compete with others in } \\
\text { school." }\end{array}$ \\
\hline & Social power & $\begin{array}{l}\text { Seeking status through group lead- } \\
\text { ership }\end{array}$ & "I like being in charge of a group." \\
\hline \multirow{2}{*}{ 3. Social goals } & Affiliation & $\begin{array}{l}\text { and belonging to a group when do- } \\
\text { ing schoolwork }\end{array}$ & $\begin{array}{l}\text { "I can do my best work at school when } \\
\text { I work with others." }\end{array}$ \\
\hline & Concern & Concern for other students & $\begin{array}{l}\text { "I like helping other students with their } \\
\text { schoolwork." }\end{array}$ \\
\hline \multirow{2}{*}{ 4. Extrinsic goals } & Token & $\begin{array}{l}\text { Seeking tangible rewards for } \\
\text { schoolwork }\end{array}$ & $\begin{array}{l}\text { "Getting a reward for my good school- } \\
\text { work is important to me." }\end{array}$ \\
\hline & Praise & $\begin{array}{l}\text { Seeking social recognition for } \\
\text { schoolwork }\end{array}$ & $\begin{array}{l}\text { "I work best when I am praised in } \\
\text { school. }\end{array}$ \\
\hline
\end{tabular}

Note. Sample items are taken from the Inventory of School Motivation.

Source: Adapted from McInerney and Liem (2009). 
to academic outcomes although the studies done are much fewer when compared to those on mastery and performance goals (e.g., Dowson \& McInerney, 2001, 2003; King, McInerney, \& Watkins, 2012b, 2013; Miller, Greene, Montalvo, Ravindran, \& Nichols, 1996; Ryan, Hicks, \& Midgley, 1997).

Aside from social goals, PI theory also takes extrinsic goals into account such as praise goals, which refers to seeking praise for schoolwork and token goals that refer to seeking for tangible rewards. Watkins, McInerney, and Lee (2002) found that token goals were positively related to surface learning strategies among students from Hong Kong, Nepal, South Africa, and Zambia. Research in self-determination theory has also shown that the pursuit of extrinsic types of goals may be detrimental to one's academic outcomes (Deci \& Ryan, 2000). Therefore, it is also important to look at extrinsic goals. Merely focusing on mastery and performance goals seems inadequate in investigating the complex phenomenon of student motivation.

\section{Construct Validation: Within and between-Network Approaches}

The applicability of PI theory has to be verified in different cultural contexts. In this study, we used a construct validation approach to test the hierarchical and multidimensional model of motivational goals in the Philippine setting. Studies that adopt this approach can be classified as within-network or between-network studies (e.g., Ganotice \& King, 2013; King \& Watkins, 2011). Within-network construct validation, also called internal construct validation, refers to the examination of the factor structure and the factor correlation matrix. It typically involves statistical techniques such as confirmatory factor analysis (CFA) and reliability analysis. On the other hand, between-network or external construct validation approach involves examining patterns of relationships between the scales and other theoretically related constructs using statistical techniques such as correlational or regression analysis. Few studies adopt this dual approach to validity, thereby providing relatively limited input into understanding the constructs being investigated. In this study, both approaches are used.

\section{The present study}

The aim of this study was to assess the cross-cultural validity in the Philippine setting of the hierarchical and multidimensional model of motivational goals proposed in PI theory, using both within-network and between-network approaches to construct validation. For the within-network study, we examined the factor structure of the Inventory of School Motivation (ISM) using standard confirmatory factor analysis techniques. We compared the proposed multidimensional and hierarchical model with a series of alternative models. We hypothesized that the structure of students' goals could be described as hierarchical and multidimensional in line with the theorizing in PI Theory. The eight first order goals (task, effort, competition, social power, social affiliation, social concern, praise, and token) were hypothesized to load onto their respective second order goals - mastery (task and effort), performance (competition and social power), social (social affiliation and social concern), and extrinsic (praise and token) goals. These second order goals, in turn, would load onto a third-order global motivation factor.

For the between-network study, we analyzed the relationship of the different goals to theoretically-relevant variables such as academic achievement and affect to school. We hypothesized that mastery and performance goals would be positively related to academic achievement. This is in concordance with the results of a recent meta-analysis conducted by Hulleman et al. (2010) which showed that both mastery and performance goals were positively related to performance outcomes.

No specific hypotheses were advanced with regard to social goals and extrinsic goals given the scarcity of research on these two types of goals.

\section{Methods}

\section{Participants}

Participants were 823 high school students from one public secondary school in Manila, Philippines. The average age of the students was $14.28(S D=0.97)$. 
There were 361 males and 462 females. All students were in their third year when the study was conducted. The secondary school - where students were recruited - was a large government-funded institution in the capital. It had over 4.000 students, from first year to fourth year. Note that in the Philippine educational system, there are six years of primary school and four years of high school before students proceed to tertiary education. Most of the students in this school came from low class and lower- middle class families.

\section{Instruments}

In this study, we used the Filipino-language version (Ganotice, Bernardo, \& King, 2012) of the Inventory of School Motivation (ISM). The ISM is a 43-item instrument designed to measure the different types of goals proposed in PI Theory. It is anchored on a 5-point Likert scale $(1=$ Strongly Disagree; 5 = Strongly Agree) with higher scores indicating a greater degree of endorsement for a certain goal. The ISM measures eight types of goals: task, effort, competition, social power, social affiliation, social concern, praise, and token which could be subsumed by four higher-order goals: mastery (task and effort), performance (competition and social power), social (social affiliation and social concern), and extrinsic (praise and token).

Previous studies have shown that this instrument is valid in the Philippine setting (Ganotice, 2010a; King, Ganotice, \& Watkins, 2012; Watkins, McInerney, \& Boholst, 2003). For example, Ganotice, Bernardo, and King (2012b) reported Cronbach's alpha coefficients of 0.76 for mastery, 0.81 for performance, 0.72 for social, and 0.85 for extrinsic goals in the Philippines.

\section{Academic Achievement}

Students' academic achievement was measured through an objective Chemistry achievement test. It contains 75 items using a multiple choice format which aims to measure the chemistry knowledge of students. Chemistry was chosen because all third year high school students in the Philippines are required to study chemistry as part of the curriculum, and all participants in this study were third year high school students. Items were formulated based on the minimum learning competencies established by the Department of Education of the Philippine government. Ganotice's (2010b) study found this test to be a valid measure of Filipino high school students' chemistry knowledge.

\section{Affect to school}

This construct was measured through the Affect to School subscale of the Facilitating Conditions Questionnaire ([FCQ]; Dowson, McInerney, \& Yeung, 2005). The FCQ is a 55-item questionnaire that contains 11 subscales measuring different constructs (university intention, school valuing, parent support, teacher support, peer help, leave school, pride from others, negative parent influence, affect to school, negative peer influence, positive peer influence). However, in this study we only focus on the affect to school subscale which measures the degree to which students like school or not. The FCQ is also measured on a 5-point Likert scale $(1=$ Strongly Disagree; 5 = Strongly Agree $)$ with higher scores indicating a greater degree of endorsement for a certain goal. A total of three items comprised the affect to school subscale.

The FCQ has been found to be valid in a previous study among Filipino students (Ganotice et al., 2012a). For example, Ganotice et al. (2012a) obtained a mean Cronbach's alpha coefficient of 0.86 for the different subscales in the FCQ, with Cronbach's alphas ranging from 0.77 to 0.9. In particular, they found that the affect to school subscale had a Cronbach's alpha of 0.77.

\section{Administration Procedures}

The second author administered the relevant questionnaires to participants in class groups with the assistance of teachers at each school. Teachers were instructed to not interpret any of the items for students, but to tell students to interpret the items as best as they could or leave it blank if they 
did not understand it. Participants were recruited through a convenience sampling of the third year high school classes.

\section{Statistical Analysis}

Confirmatory factor analysis (CFA) was conducted and maximum likelihood was the method of estimation used. The CFA procedure was used to assess the extent to which the observed data reflected or fit the proposed multidimensional and hierarchical structure of the 43-item ISM. Bagozzi and Heatherton (1994) suggested that it is quite likely that having more than five indicators per factor in a large sample would lead to an unsatisfactory fit in the measurement model. To address this issue, we combined the items to form item "parcels" as indicators in the CFA (Little, Cunningham, Shahar, \& Widaman, 2002). A parcel is defined as an indicator comprised of the sum or average of two or more items, responses, or behaviors. To create the parcels, we randomly assigned each item in a factor to one parcel. A random assignment of two to four items to parcels should, on average, lead to parcels that contain roughly equal common factor variance (Little et al., 2002). Using parcels is believed to increase the reliabilities of the indicator variables, and reduces the likelihood that parameters will be affected by item-specific variance (Lance, Woehr, \& Fisicaro, 1991). Moreover, the distribution of the parcels are more likely to resemble a normal distribution.

TABLE 2

Bivariate Correlations among the First-Order Goals

\begin{tabular}{|c|c|c|c|c|c|c|c|c|}
\hline & 1 & 2 & 3 & 4 & 5 & 6 & 7 & 8 \\
\hline 1. Task goals & $\ldots$ & $0.883^{* * * *}$ & $0.879^{* * * *}$ & $0.878^{* * * *}$ & $0.165^{* * * *}$ & $0.108^{* *}$ & $0.536^{* * * *}$ & $0.56^{* * * *}$ \\
\hline 20. Effort goals & & ... & $0.896^{* * * *}$ & $0.887^{* * * *}$ & $0.165^{* *}$ & $0.135^{* * * *}$ & $0.509^{* * *}$ & $0.558^{* * *}$ \\
\hline 30. Competition goals & & & ... & $0.945^{* * *}$ & $0.172^{* * * *}$ & $0.178^{* * * *}$ & $0.553^{* * *}$ & $0.58^{* * * *}$ \\
\hline 40. Social power & & & & $\ldots$ & $0.153^{* * * *}$ & $0.138^{* * * *}$ & $0.514^{* * * *}$ & $0.553^{* * * *}$ \\
\hline 50. Social affiliation & & & & & .. & $0.436^{* * * *}$ & $0.262^{* * *}$ & $0.234^{* * * *}$ \\
\hline 60. Social concern & & & & & & $\ldots$ & $0.192^{* * * *}$ & $0.203^{* * * *}$ \\
\hline 70. Praise goals & & & & & & & ... & $0.848^{* * *}$ \\
\hline 8. Token goals & & & & & & & & $\ldots$ \\
\hline Mean & 3.91 & 3.62 & 3.42 & 3.25 & 3.8 & 3.9 & 3.83 & 3.52 \\
\hline SD & 1.02 & 1 & 1.28 & 1.34 & 0.69 & 0.62 & 1.02 & 0.95 \\
\hline Cronbach's alpha & 0.91 & 0.91 & 0.96 & 0.97 & 0.66 & 0.68 & 0.92 & 0.89 \\
\hline
\end{tabular}

$* * p<0.01 ; * * * p<0.001$.

Source: Own work.

TABLE 3

Bivariate Correlations among the Second-Order Goals

\begin{tabular}{lcccc}
\hline & Mastery & Performance & Social & Extrinsic \\
\hline 1. Mastery & $\cdots$ & $0.92^{* * * *}$ & $0.169^{* * * *}$ & $0.579^{* * * *}$ \\
2. Performance & & $\cdots$ & $0.19^{* * * *}$ & $0.578^{* * * *}$ \\
3. Social & & & $\cdots$ & $0.264^{* * * *}$ \\
4. Extrinsic & & & & $\ldots$ \\
\hline Mean & 3.73 & 3.34 & 3.87 & 3.65 \\
SD & 0.98 & 1.29 & 0.55 & 0.94 \\
Cronbach's alpha & 0.95 & 0.98 & 0.75 & 0.94 \\
\hline
\end{tabular}

$* * * p<0.001$.

Source: Own work. 
The results based on parcels are more likely to be stable (i.e. generalizable) across samples (West, Finch, \& Curran, 1995). Twenty-four parcels were created from the 43 items of the Inventory of School Motivation. There were two to three randomly assigned items for each parcel, with the average of the items being used as the parcel score.

Several goodness-of-fit indices were used to determine the model fit based on the understanding that multiple indices provided a comprehensive evaluation of model fit (Hu \& Bentler, 1995, 1999). The following fit indices used were: root mean square error approximation (RMSEA), goodness of fit index (GFI), comparative fit index (CFI), normed fit index (NFI), incremental fit index (IFI), Tucker-Lewis Index (TLI), and the comparative fit index (CFI). The criterion values were set based on the prescriptions summarized by Byrne (2010). For the RMSEA, values less than 0.08 indicate an acceptable fit. GFI, NFI, IFI, TLI, and CFI values higher than 0.9 shows acceptable fit.

\section{Results}

Descriptive statistics and Cronbach's alpha reliabilities are presented in Table 2 together with the correlations among the first-order goals. Most of the Cronbach's alphas were in the 0.7 to $0.9 \mathrm{~s}$ range. Social affiliation and social concern goals had somewhat lower reliabilities, although they can still be considered acceptable (Nunally \& Bernstein, 1994). Table 3 depicts the bivariate correlations among the second-order goals. Scores for the second order goals were derived by getting the mean of the first order goals that comprise it.

TABLE 4

Fit Indices for the Different CFA Models

\begin{tabular}{|c|c|c|c|c|c|c|c|c|c|c|c|c|}
\hline Model & $\chi^{2}$ & $d f$ & $\chi^{2} / d f$ & $p$ & RMSEA & GFI & NFI & TLI & CFI & $\begin{array}{l}\text { Change } \\
\text { in } \chi^{2}\end{array}$ & $\begin{array}{c}\text { Change } \\
\text { in } d f\end{array}$ & \\
\hline 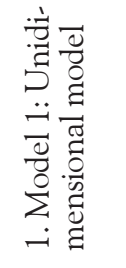 & 4738.614 & 252 & 18.804 & $<0.001$ & 0.147 & 0.569 & 0.756 & 0.744 & 0.766 & & & \\
\hline 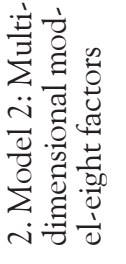 & 653.265 & 224 & 2.916 & $<0.001$ & 0.048 & 0.938 & 0.966 & 0.972 & 0.978 & 4085.349 & 28 & $<0.001$ \\
\hline 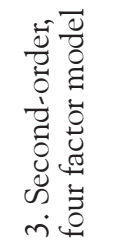 & 699.658 & 238 & 2.94 & $<0.001$ & 0.049 & 0.934 & 0.964 & 0.972 & 0.976 & 46.393 & 14 & $<0.001$ \\
\hline 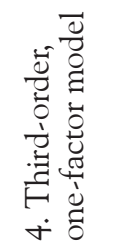 & 730.714 & 241 & 3.032 & $<0.001$ & 0.05 & 0.931 & 0.962 & 0.971 & 0.974 & 77.449 & 17 & $<0.001$ \\
\hline
\end{tabular}

Source: Own work. 


\section{Within-Network Study}

To test the within-network construct validity, a series of CFA models were tested. Model 1 was a one dimensional model where all the items were presumed to load only onto one general factor. Model 2 proposed that there were eight types of motivational goals but had no second or third order factors. Model 3 included four second-order factors that could subsume the eight first-order factors. It $\mathrm{M}$ proposed that there were eight types of motivational goals that could be subsumed into four second-order goals, which in turn could be subsumed by a global motivation third-order factor. Model 4 proposed a third-order factor called global motivation that could subsume the second-order factors of mastery, performance, social, and extrinsic goals, which in turn was underpinned by eight first-order factors. Table 4 shows the fit indices for the different CFA models.

The results indicated that the unidimensional model did not fit the data well. However, Model 2, Model 3, and Model 4, all fit the data well with RMSEA's all less than the cutoff of 0.08 and CFI, $\mathrm{NFI}$, and TLI all higher than 0.9. We did chi-square difference tests between Models 1 and 2, 2 and 3, and 3 and 4 . We found that there were significant differences among these models as shown in the significant chi-square difference tests.

Given that PI theory proposes Model 4 (third-order, one factor model) and that this model is the most parsimonious of all the possible models, we decided to adopt this model. All the loadings in this model were significant at the $p<0.001$ level. It should be noted that Models 2 and 3 also fit the data well and are equally valid from a purely statistical perspective. However, from a theoretical perspective, Model 4 is more meaningful given that this is in line with findings of PI theory.

\section{Between-Network Study}

For the between-network study, we assessed the relationship of the different motivational goals to academic achievement and affect to school which is shown in Table 5

An interesting pattern was the positive correlation of both mastery and performance goals with academic achievement. This is in line with our hypothesis, as well as with the results of the meta-anal-

TABLE 5

Zero-Order Correlations between Goals in the ISM and Between-Network Measures

\begin{tabular}{lcc}
\hline \multicolumn{1}{c}{ First-order goal } & Achievement Test & Affect to school \\
\hline 1 Task goals & $0.31^{* * *}$ & 0.032 \\
2 Effort goals & $0.3^{* * *}$ & 0.006 \\
3 Competition goals & $0.278^{* * *}$ & 0.014 \\
4 Social power goals & $0.301^{* *}$ & 0 \\
5 Affiliation goals & 0.004 & $0.155^{* * *}$ \\
6 Concern goals & 0.031 & $0.14^{* * *}$ \\
7 Praise goals & $0.102^{* *}$ & $0.112^{* * *}$ \\
8 Token goals & $0.117^{* * *}$ & $0.085^{*}$ \\
\hline \multicolumn{1}{c}{ Second-order goals } & & \\
\hline 1. Mastery goals & $0.312^{* * *}$ & 0.016 \\
2. Performance goals & $0.294^{* * *}$ & 0.007 \\
3. Social goals & 0.024 & $0.17^{* * *}$ \\
4. Extrinsic goals & $0.114^{* * * *}$ & $0.1 * *$ \\
Third-order goal & & \\
Global motivation & $0.263^{* * *}$ & $0.07^{*}$ \\
\hline
\end{tabular}

$* p<0.05 ; * *<<0.01 ; * * p<0.001$.

Source: Own work. 
ysis conducted by Hulleman et al. (2010). However, they were not significantly correlated with positive affect in school. Social goals, on the other hand, were positively correlated with affect to school but not with academic achievement. Extrinsic goals and global motivation (the third order factor) were positively correlated with both academic achievement and positive affect to school.

\section{Discussion}

This study showed the cross-cultural applicability of the hierarchical and multidimensional model of student motivation posited in PI Theory within the Philippine context. This model depicts eight types of first-order goals that could be subsumed by four second-order goals. These second-order goals, in turn, could be subsumed by a more general global motivation factor.

This study extends previous findings on the validity of the PI framework which has been tested among Australian, American, Chinese, African, Aboriginal Australian, and Native American students (McInerney \& Ali, 2006). Although studies assessing the different goals measured in the ISM have been previously conducted in various settings, these earlier studies have mostly confined themselves to using exploratory factor analysis or first-order CFA (e.g., Ganotice et al., 2012; King et al., 2012; Watkins et al., 2003). This study contributes to the literature by specifically testing the hierarchical and multidimensional nature of motivational goals.

A hierarchical and multidimensional conceptualization of motivational goals has several distinct advantages compared to alternative models wherein goals are just assumed to be distinct first-order constructs. First, a hierarchical model is more parsimonious compared to a model wherein all the different types of goals are just posited to be related to one another without any organizing structure. Parsimony has always been valued in scientific research given that such models can explain a complex phenomenon in simpler terms. Second, a hierarchical structure would allow researchers to conduct analysis at different levels of specificity, depending on the specific interest. For example, in intervention programs designed to facilitate certain specific types of goals, it might be more useful to look at how the intervention relates to the first-order goals. An example that comes to mind would be cooperative and collaborative forms of learning wherein social goals, such as affiliation and concern, would be more likely to improve. Intervention programs that aim to decrease interpersonal competitiveness in classroom settings could also use the ISM in order to check whether performance-oriented goals, such as competition and social power goals, really declined. However, when the focus is on getting a more general picture of student motivation, it might be sufficient to just look at the second-order factors. Policy makers who are just concerned with getting an idea of whether students are motivated or not, might focus more on the third-order global motivation construct. They can get an overall idea of how engaged students are in schools without needing to burden themselves with the details.

In terms of the within-network study, the CFA showed that the hierarchical and multidimensional model had good fit indices. Most of the scales had adequate reliabilities except for the two types of social goals - affiliation and concern — which had reliabilities that were lower than ideal. A possible problem with slightly lower reliabilities of these scales would be the difficulty in conceptualizing and operationalizing them. As Urdan and Maehr (1995) noted in their landmark review, social goals are still fuzzy constructs in the literature (for reviews see also King \& McInerney, 2012; King \& Watkins, 2012). Future research could look into possible ways of operationalizing social goals in a more precise manner (for an example see King \& Watkins, 2012).

In terms of the between-network study, we found that the different types of motivational goals were positively correlated to two outcome measures-achievement and affect to school. It is interesting to note that the two types of social goals (social affiliation and social concern goals) were positively correlated with affect to school, although their relationship with achievement was non-significant. The opposite was the case for 
mastery (task and effort goals) and performance goals (competition and social power goals), which were both positively related to achievement but not affect to school. Extrinsic goals (token and praise goals), on the other hand, were positively related to both achievement and affect. These divergent correlation patterns would suggest that different types of goals would lead to different outcomes. It seems possible that although social goals were not directly related to achievement, the pursuit of social goals helped students to feel more positive in school settings. These patterns would not be discovered, had we relied solely on measuring mastery and performance goals.. Future research is needed to look into the nomological network associated with social goals (King \& McInerney, 2012).

The positive correlation of extrinsic goals to both achievement and affect to school might be related with the current cultural context where the study was conducted. The Philippines is considered a collectivist culture. Extrinsic motivation has been shown to be associated with positive outcomes in collectivist cultures, but in individualistic cultures extrinsic motivation has usually been associated with maladaptive outcomes (see, Deci \& Ryan, 2000). Researchers have hypothesized that this may be possibly due to the greater tendency of students from collectivist cultures to internalize extrinsic goals such that they can be pursued in a very autonomous manner (Iyenggar \& Lepper, 1999)

An interesting finding was the high correlation between mastery and performance goals in the Philippine setting. Previous studies in Western contexts have usually regarded them as distinct goals (Elliot, 1999; Elliot \& Church, 1997; Elliot \& Murayama, 2008). However, research in Asian settings has always shown them to be strongly positively correlated. This was also the case with the current study. Tao and Hong (2000) proffered a meaning-system approach to the study of achievement goals. They found that both mastery and performance goals were positively correlated among collectivist students. In collectivist cultures, wanting to achieve, because one likes the subject matter (mastery goals), is not incompatible with wanting to demonstrate that one is better than others (performance goals).
This is a possible reason why the relationship between these two goals was quite high for the Filipino students. Similar positive correlations have been found in other collectivist settings such as those in China, Singapore, and Japan (Bernardo, 2008; Bernardo \& Ismail, 2010; dela Rosa, 2010; dela Rosa \& Bernardo, 2013; Chan \& Lai, 2006; Chan, Lai, Leung, \& Moore, 2005; Chang \& Wong, 2008; Ho \& Hau, 2008; Kim et al., 2010; Lau, Liem, \& Nie, 2008; Shi et al., 2001; Tanaka, Okuno, \& Yamauchi, 2002).

\section{Limitations and Directions for Future Research}

We would like to acknowledge that like any other research, this study has some limitations. Our study only involved secondary high school students from the Metro Manila area. Future studies could include participants from other districts which would make the sample more representative. Moreover, future studies could also include a wider range of between-network measures beyond academic achievement and affect to school.

\section{Conclusion}

Students' goals are considered important predictors of engagement and achievement. The most dominant framework for investigating goals in the educational literature is achievement goal theory, which has been found to be limited - especially when applied to collectivist cultures - given the restricted range of goals that it examines. Thus, PI theory offers a better alternative in studying motivational goals in diverse cultural settings. PI theory includes mastery and performance goals which have been the traditional focus of achievement goal theorists. Moreover, it also examines social and extrinsic goals which have been found to be salient in collectivist cultures.

In this study, we tested the cross-cultural applicability of the theoretical propositions of PI theory in the Philippine setting. Testing for applicability is important because previous research has shown that achievement motivation theories drawn from 
Western literature are not always completely applicable to non-Western contexts (Elliot, Chirkov, Kim, \& Sheldon, 2001; King, McInerney, \& Watkins, 2012a; Lockwood, Marshall, \& Saddler, 2005; Yu \& Yang, 1994). Overall, this study supported the cross-cultural validity of the PI framework. Future studies could be conducted to determine the applicability of this theory in other cultural contexts.

\section{References}

Ames, C. A. (1992). Classrooms: Goals, structures, and student motivation. Journal of Educational Psychology, 84(3), 261-271.

Bagozzi, R. P., \& Heatherton, T. F. (1994). A general approach to representing multifaceted personality constructs: Application to state self-esteem. Structural Equation Modeling, 1(1), 25-67.

Bernardo, A. B. I. (2008). Individual and social dimensions of Filipino students' achievement goals. International Journal of Psychology, 43(5), 886-891.

Bernardo, A. B. I., \& Ismail, R. (2010). Social perceptions of achieving students and achievement goals of students in Malaysia and the Philippines. Social Psychology of Education, 13(3), 385-407.

Boekaerts, M. (2006). Goal-directed behaviour and contextual factors in the classroom: An innovative approach to the study of multiple goals. Educational Psychologist, 41(1), 33-51.

Boekaerts, M. (2009). Goal-directed behaviour in the classroom. In K. Wentzel \& A. Wigfield (Eds.), Handbook of motivation at school (pp. 105-122). New York: Routlege.

Byrne, B. M. (2010). Structural equation modelling with AMOS: Basic concepts, applications, and programming (2nd ed.). New York: Routledge.

Chan, K. W., \& Lai, P. Y. (2006). Revisiting the trichotomous achievement goal framework for Hong Kong secondary students: A structural model analysis. The Asia-Pacific Education Researcher, 16(1), 11-22.

Chan, K. W., Lai, P. Y., Leung, M. T., \& Moore, P. J. (2005). Students' goal orientations, study strategies and achievement: A closer look in Hong Kong Chinese cultural context. The Asia-Pacific Education Researcher, 14(1), 1-26.
Chang, W. C., \& Wong, K. (2008). Socially oriented achievement goals of Chinese university students in Singapore: Structure and relationships with achievement motives, goals, and affective outcomes. International Journal of Psychology, 43(5), 880-885.

Covington, M. V. (2000). Goal theory, motivation, and school achievement: An integrative review. Annual Review of Psychology, 51(1), 171-200.

Deci, E. L., \& Ryan, R. M. (2000). The "what" and "why" of goal pursuits: Human needs and the selfdetermination of behavior. Psychology Inquiry, 11(4), $227-268$.

Dela Rosa, E. (2010). The 2 x 2 achievement goal framework and intrinsic motivation among Filipino students: A validation study. Educational Measurement and Evaluation Review, 1(1), 48-58.

Dela Rosa, E., \& Bernardo, A. B. I. (2013). Testing multiple goals theory in an Asian context: Filipino university students' motivation and academic achievement. International Journal of School \& Educational Psychology, 1(1), 47-57.

Dowson, M., \& McInerney, D. M. (2001). Psychological parameters of students' social and work avoidance goals: A qualitative investigation. Journal of Educational Psychology, 93(1), 35-42.

Dowson, M., \& McInerney, D. M. (2003). What do students say about their motivational goals? Towards a more complex and dynamic perspective on student motivation. Contemporary Educational Psychology, 28(1), 91-113.

Dowson, M., McInerney, D. M., \& Yeung, A. S. (2004). Facilitating conditions for school motivation: Construct validity and applicability. Educational and Psychological Measurement, 65(6), 1046-1066.

Dweck, C. S., \& Leggett, E. L. (1988). A social-cognitive approach to motivation and personality. Psychological Review, 95(2), 256-273.

Eccles, J. S., Wigfield, A., \& Schiefele, U. (1998). Motivation. In N. Eisenberg (Ed.), Handbook of child psychology (5th ed., Vol. 3, pp. 1075-1095). New York: Wiley.

Elliot, A. J. (1999). Approach and avoidance motivation and achievement goals. Educational Psychologist, 34(3), 149-169. 
Elliot, A. (2005). A conceptual history of the achievement goal construct. In A. J. Elliot \& C. S. Dweck (Eds.), Handbook of competence and motivation (pp. 52-72). New York: Guilford Press.

Elliot, A. J., Chirkov, V. I., Kim, Y., \& Sheldon, K. M. (2001). A cross-cultural analysis of avoidance (relative to approach) personal goals. Psychological Science, 12(6), 505-510.

Elliot, A. J., \& Church, M. A. (1997). A hierarchical model of approach and avoidance achievement motivation. Journal of Personality and Social Psychology, 72(1), 218-232.

Elliot, A. J., \& Murayama, K. (2008). On the measurement of achievement goals: Critique, illustration, and application. Journal of Educational Psychology, 100(3), 613-628.

Ganotice, F. A. (2010a). A confirmatory factor analysis of scores on Inventory of School Motivation (ISM), Sense of Self Scale, and Facilitating Conditions Questionnaire (FCQ): A study using a Philippine sample. Educational Measurement and Evaluation Review, 1(1), 59-77.

Ganotice, F. A. (2010b). Personal investment and school achievement among adolescent students in public and private high schools in the Philippines. Unpublished doctoral dissertation, De La Salle University, Manila, Philippines.

Ganotice, F. A., Bernardo, A. B. I., \& King, R. B. (2012a). Adapting the Facilitating Conditions Questionnaire (FCQ) for bilingual Filipino adolescents: Validating the English and Filipino versions. Child Indicators Research, 6(2), 237-256. doi: 10.1007/ s12187-012-9167-1

Ganotice, F. A., Bernardo, A. B. I., \& King, R. B. (2012b). Testing the factorial invariance of the English and Filipino version of the Inventory of School Motivation with bilingual students in the Philippines. Journal of Psychoeducational Assessment, 30(3), 298-303.

Ganotice, F. A., \& King, R. B. (2013). Blessed are those who wait: Validating the Filipino version of the Academic Delay of Gratification Scale (ADOGS). The Asia-Pacific Education Researcher. Advance online publication. doi: 10.1007/s40299-013-0081-1

Ho, I. T., \& Hau, K. T. (2008). Academic achievement in the Chinese context: The role of goals, strate- gies, and effort. International Journal of Psychology, 43(5), 892-897.

Hu, L. T., \& Bentler, P. M. (1995). Measuring model fit. In R. H. Hoyle (Ed.), Structural equation modeling: Concepts, issues and applications (pp. 76-99). Thousand Oaks, CA: Sage.

Hu, L. T., \& Bentler, P. M. (1999). Cutoff criteria for fit indexes in covariance structure analysis: Conventional criteria versus new alternatives. Structural Equation Modeling, 6(1), 1-55.

Hulleman, C. S., Schrager, S. M., Bodmann, S. W., \& Harackiewicz, J. M. (2010). A meta-analytic review of achievement goal measures: Different labels for the same constructs or different constructs with similar labels? Psychological Bulletin, 136(3), 422-449.

Iyenggar, S. S., \& Lepper, M. R. (1999). Rethinking the value of choice: A cultural perspective on intrinsic motivation. Journal of Personality and Social Psychology, 76(3), 349-366.

Kim, J. I., Schallert, D. L., \& Kim, M. (2010). An integrative cultural view of achievement motivation: Parental and classroom predictors of children's goal orientations when learning mathematics in Korea. Journal of Educational Psychology, 102(2), 418-437.

King, R. B., Ganotice, F. A., \& Watkins, D. A. (2012). Cross-cultural validity of the Inventory of School Motivation (ISM) in Chinese and Filipino samples. Child Indicators Research, 5(1), 135-153.

King, R. B., \& McInerney, D. M. (2012). Including social goals in achievement motivation research: Examples from the Philippines. Online Readings in Psychology and Culture, Unit 5. Retrieved from http://scholarworks.gvsu.edu/orpc/vol5/iss3/4

King, R. B., McInerney, D. M., \& Watkins, D. A. (2012a). Competitiveness is not that bad... at least in the East: Testing the hierarchical model of achievement motivation in the Asian setting. International Journal of Intercultural Relations, 36(3), 446-457.

King, R. B., McInerney, D. M., \& Watkins, D. A. (2012b). Studying for the sake of others: The role of social goals on academic engagement. Educational Psychology, 32(6), 749-776.

King, R. B., McInerney, D. M., \& Watkins, D. A. (2013). Examining the role of social goals in school: A study in two collectivist cultures. European Journal of Psy- 
chology of Education. Advance online publication. doi: 10.1007/s10212-013-0179-0

King, R. B., \& Watkins, D. A. (2011). The reliability and validity of the Goal Orientation and Learning Strategies Survey: A Filipino investigation. The Asia Pacific Education Researcher, 20(3), 591-606.

King, R. B., \& Watkins, D. A. (2012a). Cross-cultural validation of the five-factor structure of social goals. Journal of Psychoeducational Assessment, 30(2), 181 193.

King, R. B., \& Watkins, D. A. (2012b). "Socializing" achievement goal theory: The case for social goals. Psychological Studies, 57(1), 112-116.

Lance, C. E., Woehr, D. J., \& Fisicaro, S. A. (1991). Cognitive categorization processes in performance evaluation: Confirmatory tests of two models. Journal of Organizational Behavior, 12(1), 1-20.

Lau, S., Liem, A. D., \& Nie, Y. (2008). Task-and selfrelated pathways to deep learning: The mediating role of achievement goals, classroom attentiveness, and group participation. British Journal of Educational Psychology, 78(4), 639-662.

Little, T. D., Cunningham, W. A., Shahar, G., \& Widaman, K. F. (2002). To parcel or not to parcel: Exploring the question weighing the merits. Structural Equation Modeling, 9(2), 151-173.

Lockwood, P., Marshall, T. C., \& Sadler, P. (2005). Promoting success or preventing failure: Cultural differences in motivation by positive and negative role models. Personality and Social Psychology Bulletin, 31(3), 379-392.

Maehr, M. L. (1984). Meaning and motivation: Toward a theory of personal investment. In R. Ames \& C. Ames (Eds.), Research on motivation in education: Student motivation (Vol. 1, pp. 115-144). New York: Academic Press.

Maehr, M. L., \& McInerney, D. M. (2004). Motivation as personal investment. In D. M. McInerney \& S. Van Etten (Eds.), Big theories revisited (pp. 61-90). Greenwich, CO: Information Age Pub.

Maehr, M. L., \& Zusho, A. (2009). Achievement goal theory: The past, present, and future. In K. Wentzel \& A. Wigfield (Eds.), Handbook of motivation at school (pp. 77-104). New York: Routlege.

McInerney, D., \& Ali, J. (2006). Multidimensional and hierarchical assessment of school motivation:
Cross-cultural validation. Educational Psychology, 26(6), 717-734.

McInerney, D. M., \& Liem, G. A. D. (2009). Achievement motivation in cross-cultural context: Application of personal investment theory in educational settings. In A. Kaplan, S. A. Karabenick, \& E. De Groot (Eds.), Culture, self, and motivation: Essays in honour of Martin L. Maehr (pp. 213-241). Greenwich, CT: Information Age Publishing.

McInerney, D. M., \& Van Etten, S. (Eds.). (2004). Research on sociocultural influences on motivation and learning. Greenwich, CT: Information Age.

Miller, R. B., Greene, B. A., Montalvo, G. P., Ravindran, B., \& Nichols, J. D. (1996). Engagement in academic work: The role of learning goals, future consequences, pleasing others, and perceived ability. Contemporary Educational Psychology, 21(4), 388-422.

Nunnally, J., \& Bernstein, I. (1994). Psychometric theory. New York: McGraw Hill.

Pintrich, P. R. (2000). Multiple goals, multiple pathways: The role of goal orientation in learning and achievement. Journal of Educational Psychology, 92(3), 544-555.

Pintrich, P. R. (2003). A motivational science perspective on the role of student motivation in learning and teaching contexts. Journal of Educational Psychology, 95(4), 667-686.

Ryan, A. M., Hicks, L., \& Midgley, C. (1997). Social goals, academic goals, and avoiding seeking help in the classroom. Journal of Early Adolescence, 17(2), 152-171.

Salili, F., \& Hoosain, R. (Eds.). (2007). Teaching, learning, and motivation in a multicultural context (Vol. 6). Greenwich, CT: Information Age.

Shi, K., Wang, P., Wang, W., Zuo, Y., Liu, D., Maehr, M., et al. (2001). Goals and motivation of Chinese students: Testing the adaptive learning model. In F. Salili, C. Y. Chiu, \& Y. Y. Hong (Eds.), Student motivation: The culture and context of learning (pp. 249-270). London: Kluwer Academic/Plenum Publishers.

Tanaka, A., Okuno, T., \& Yamauchi, H. (2002). Achievement motives, cognitive and social competence, and achievement goals in the classroom. Perceptual and Motor Skills, 95(2), 445-458. 
Tao, Y. C. (2003). Hong Kong Chinese students' learning motivation: The role of social versus individual-oriented achievement motivation. Unpublished doctoral dissertation, Hong Kong University of Science and Technology, Hong Kong.

Tao, V., \& Hong, Y. Y. (2000). A meaning system approach to Chinese students' achievement goals. Journal of Psychology in Chinese Societies, 1(2), 13-38.

Urdan, T., \& Maehr, M. L. (1995). Beyond a two-goal theory of motivation and achievement: A case for social goals. Review of Educational Research, 65(3), 213-243.

Watkins, D., McInerney, D., \& Boholst, F. (2003). The reliability and validity of the Inventory of School Motivation: A Filipino investigation. The Asia Pacific Education Researcher, 12(1), 87-100.
Watkins, D., McInerney, D. M., \& Lee, C. (2002). Assessing the school motivation of Hong Kong students. Psychologia, 45(3), 144-154.

West, S. G., Finch, J. F., \& Curran, P. J. (1995). Structural equation models with non-normal variables: Problems and remedies. In R. H. Hoyle (Ed.), Structural equation modelling: Concepts, issues, and applications (pp. 56-75). Thousand Oaks, CA: Sage.

Yu, A. B., \& Yang, K. S. (1994). The nature of achievement motivation in collectivist societies. In U. Kim, H. C. Triandis, C. Kagitcibasi, S. C. Choi, \& G. Yoon (Eds.), Individualism and collectivism: Theory, method and applications (pp. 239-250). Thousand Oaks, CA: Sage. 